\title{
A gestão do sistema de proteção à propriedade intelectual no Brasil é consistente?*
}

\author{
José Matias-Pereira**
}

SumÁrio: 1. Introdução; 2. Dinâmica do crescimento e processo de industrialização; 3. Invenções e inovações tecnológicas e propriedade intelectual; 4. Indicadores de ciência, tecnologia e inovação do Brasil; 5. Propriedade intelectual e registro de patentes no mundo; 6 . Ranking de registro de patentes do USPTO e do PCT/WIPO; 7. Políticas públicas de proteção à propriedade intelectual; 8. Processo de modernização do Instituto Nacional da Propriedade Industrial (Inpi); 9. Percepção dos empresários sobre inovação e propriedade intelectual: análise dos resultados da pesquisa qualitativa; 10 . Conclusões.

Summary: 1 . Introduction; 2. Dynamics of growth and industrialization process; 3. Inventions and innovations and intellectual property; 4. Indicators of Science, Technology and Innovation in Brazil; 5. Intellectual property and patents in the world; 6. Ranking the USPTO patent registration and the PCT / WIPO; 7. Public policies to protect intellectual property; 8. Modernization process of the National Institute of Industrial Property; 9. Perception of entrepreneurs about innovation and intellectual property: analysis of the results of qualitative research; 10. Conclusions.

Palavras-chave: política industrial e tecnológica; propriedade intelectual; marcas e patentes; desenvolvimento econômico; Brasil.

KEY WORDS: industrial policies and technology; intellectual property; trademarks and patents; economic development; Brazil.

Este artigo tem como objetivo avaliar o nível de desempenho da gestão do sistema de proteção à propriedade intelectual no Brasil, em particular o registro de patentes

\footnotetext{
* Artigo recebido em jul. 2009 e aceito em dez. 2010.

** Economista e advogado. Doutor em ciência política - área de governo e administração pública - pela Faculdade de Ciências Políticas e Sociologia da Universidade Complutense de Madri, Espanha. Pós-doutorado em administração pela Faculdade de Economia, Administração e Contabilidade da Universidade de São Paulo (FEA/USP). Professor-pesquisador associado do Programa de PósGraduação em Contabilidade da Universidade de Brasília (UnB). Endereço: SHIS QI 26, Conjunto 5, casa 22 — Lago Sul — CEP 71670-050, Brasília, DF, Brasil. E-mail: matias@unb.br.
} 
e marcas. A análise teve como base o arcabouço institucional do país na área objeto do estudo: Lei de Propriedade Industrial, de 1996; as diretrizes de Política Industrial, Tecnológica e de Comércio Exterior, de 2004; a Lei de Inovação Tecnológica, de 2005; a Lei do Bem, de 2005; a Política de Desenvolvimento Produtivo, de 2008; o Plano de Ação de Ciência, Tecnologia e Inovação para o Desenvolvimento Nacional -2007-2010. O exame dos aperfeiçoamentos que foram introduzidos no arcabouço institucional do Brasil nos últimos anos e as melhorias que provocaram na gestão das políticas públicas de proteção à propriedade intelectual revelaram que ainda existem sérias dificuldades na implementação e gestão dessas políticas, em particular no segmento de registro de marcas e patentes.

The management system for the protection of intellectual property in Brazil is consistent?

This article aims to assess the level of performance management system to protect intellectual property in Brazil, particularly the registration of patents and trademarks. The analysis was based on the institutional framework of the country in the area object of study: Law of Industrial Property of 1996, the guidelines of Industrial Policy, Technology and Foreign Trade, 2004, the Law of Technological Innovation, 2005, Law the Well, 2005, the Productive Development Policy, 2008, the Plan of Action for Science, Technology and Innovation for National Development - 2007-2010. Examination of the improvements that were introduced in the institutional framework in Brazil in recent years and the improvements that resulted in the management of public policies to protect intellectual property revealed that there are still serious difficulties in implementation and management of these policies, particularly in the segment of the record of trademarks and patents.

\section{Introdução}

A análise dos indicadores que tratam da evolução da economia mundial nas três últimas décadas revela uma forte correlação entre o crescimento da concorrência e os investimentos em ciência, tecnologia e inovação. Esse cenário sinaliza que a priorização de investimentos em ciência, tecnologia e inovação é essencial para permitir que um país alcance um nível adequado de desenvolvimento sustentável, evitando, dessa forma, utilizar-se da exploração predatória de seus recursos naturais ou humanos para elevar sua competitividade (Unesco, 2010). ${ }^{1}$

\footnotetext{
${ }^{1}$ Registre-se que a versão em português do citado relatório inclui o capítulo 1 sobre o crescente papel do conhecimento na economia global e o capítulo 5 sobre o Brasil. Veja o relatório completo em: <www.unesco.org/science/psd >.
} 
Pode-se argumentar, nesse sentido, que a utilização intensiva da ciência e tecnologia e inovação numa economia, conforme evidencia a literatura, permite a elevação da capacidade de competir, criando empreendimentos, empresas, empregos e marcas comerciais. Essa estratégia, por sua vez, tende a aumentar a interação entre política industrial e tecnológica e propriedade intelectual (Matias-Pereira e Kruglianskas, 2005). Nesse sentido, a gestão das políticas públicas de proteção à propriedade intelectual se apresenta como um instrumento importante para apoiar o crescimento econômico do país. Por sua vez, quando existem deficiências na gestão das políticas na área de proteção à propriedade intelectual, seus efeitos tendem a afetar a competitividade das empresas.

Os relatórios e discurso governamental sustentam que nos últimos cinco anos a área de C, T\&I passou a ser uma questão de Estado; o foco na política de C, T\&I foi orientado para os eixos estratégicos; foram definidos novos marcos regulatórios; criados novos instrumentos e formatos de financiamento e aperfeiçoamento da gestão dos fundos setoriais; bem como um aumento dos recursos federais para C, T\&I. Apesar desses avanços, entendemos que os resultados alcançados pelo Brasil, após oito anos de vigência dos fundos setoriais, quatro anos de vigência da Lei de Inovação Tecnológica e dois anos e meio da Lei do Bem (Lei no 11.196/2005 — Decreto oㅜ 5.798/2006), no que se refere aos resultados de registro de patentes brasileiras, são bastante inquietantes.

Sabemos que existem diversas maneiras de reduzir os possíveis custos da extensão do nível de abrangência das patentes. Entre elas destacamos duas opções: a primeira se refere ao emprego de mecanismos de abusos do poder econômico; a segunda trata da criação de ambientes institucionais que estimulem a atividade de investimentos em pesquisa e desenvolvimento por empresas que operam nesses setores através da necessária articulação governo-iniciativa privada-universidade. Entendemos que o Brasil, a partir de um efetivo esforço para melhorar a gestão de políticas de proteção à propriedade intelectual, deveria orientar-se para a segunda opção.

Diante desse contexto, torna-se possível formular a seguinte pergunta: a gestão do sistema de proteção à propriedade intelectual no Brasil é consistente?

Este artigo tem como objetivo avaliar o nível de desempenho da gestão do sistema de proteção à propriedade intelectual no Brasil, em particular o registro de patentes. Usamos como referências o estudo de Guimarães, Políticas de inovação: financiamento e incentivos, de 2006; a Lei de Propriedade Industrial, Lei no 9.279/1996 (denominada Código da Propriedade Industrial); as diretrizes de Política Industrial, Tecnológica e de Comércio Exterior, de 2004; a Lei de Inovação Tecnológica, de 2005; a Lei do Bem (Lei no 11.196/2005 
— Decreto no 5.798/2006); ; o Plano de Ação de Ciência, Tecnologia e Inovação para o Desenvolvimento Nacional - 2007-2010; e a Política de Desenvolvimento Produtivo, de 2008.

Registre-se que as 21 prioridades definidas no Plano de Ciência, Tecnologia e Inovação para o Desenvolvimento Nacional — Plano de Ação 20072010 - estão diretamente relacionadas com os quatro eixos estratégicos que norteiam a atual Política Nacional de C, T\&I: expandir, integrar, modernizar e consolidar o Sistema Nacional de Ciência e Tecnologia e Inovação (SNCTI), atuando em articulação com os governos estaduais para ampliar a base científica e tecnológica nacional; atuar de maneira decisiva para acelerar o desenvolvimento de um ambiente favorável à inovação nas empresas, fortalecendo a Política Industrial, Tecnológica e de Comércio Exterior (Pitce); fortalecer as atividades de pesquisa e inovação em áreas estratégicas para a soberania do país, em especial energia, aeroespacial, segurança pública, defesa nacional e Amazônia; e promover a popularização e o ensino de ciências a universalização do acesso aos bens gerados pela ciência, e a difusão de tecnologias para a melhoria das condições de vida da população. Está prevista no Plano a aplicação de $\mathrm{R} \$ 41$ bilhões para o período de 2007-2010. O Plano busca expressar a configuração da nova Política Nacional de Ciência, Tecnologia e Inovação, orientado para estimular o desenvolvimento econômico e social do país (Brasil, 2007).

Trata-se de um artigo teórico-empírico e exploratório. Em termos metodológicos, a pesquisa é qualitativa e bibliográfica. Registre-se que, diante da amplitude e complexidade do tema, não temos a pretensão de esgotar o assunto objeto deste estudo.

\section{Dinâmica do crescimento e processo de industrialização}

A relevância do progresso tecnológico tem sido retratada teórica e empiricamente há várias décadas, com destaque para a contribuição de Joseph Schumpeter (1982), que nas primeiras décadas do século XX demonstrou a impor-

\footnotetext{
${ }^{2}$ Lei do Bem (Lei no 11.196/2005 — Decreto no 5.798/2006). A Lei do Bem institui o Regime Especial de Tributação para a Plataforma de Exportação de Serviços de Tecnologia da Informação (Repes), o Regime Especial de Aquisição de Bens de Capital para Empresas Exportadoras (Recap) e o Programa de Inclusão Digital. A citada Lei do Bem, além de dispor sobre incentivos fiscais para a inovação tecnológica, cuida ainda de outras questões tributárias, instituindo até mesmo outros regimes especiais de tributação. No tocante aos incentivos à inovação, coube à Lei no 11.196/2005 dar cumprimento à determinação da Lei oㅡ 10.973, de dezembro de 2004.
} 
tância do processo de inovação para o crescimento do produto. Na década de 1950, Robert Solow (1988) criou as bases para a construção da teoria do crescimento econômico. No primeiro estudo, desenvolveu um modelo teórico que sustenta o fato de que sem progresso tecnológico não há crescimento sustentado do produto per capita (Solow, 1956). Para o país alcançar o progresso duradouro, é necessário que se permita que a economia possa agregar algo à produção, sem necessariamente acrescentar mais mão de obra e capital. Solow denominou essa fonte de riqueza de "progresso tecnológico". No segundo artigo, buscou demonstrar, num exercício empírico, que o progresso tecnológico foi o maior responsável pelo crescimento da economia norte-americana (Solow, 1957). Registre-se, entretanto, que aquele teórico não conseguiu explicar o que levava ao progresso tecnológico. Coube a Paul Romer (1986, 1987, 1990 e 1993), na segunda metade da década de 1980, propor nova abordagem na teoria econômica sobre o desenvolvimento. Nesses estudos seminais sobre a teoria do crescimento econômico, incorporou a inovação tecnológica, ou seja, a produção de ideias, como o principal impulsionador do crescimento. Por sua vez, Warsh (2006) sustenta que Romer ampliou o campo de percepção da ciência econômica para capturar um mundo - a economia do conhecimento - expresso até então de forma muito vaga.

Para a compreensão de fenômenos associados à mudança econômica nos apoiamos na teoria evolucionária (Nelson e Winter, 1982, 2005). Para essa linha de pensamento, são as competências dos agentes econômicos que determinam seu comportamento, tendo como parâmetro uma racionalidade que é limitada. Na perspectiva evolucionária, o capitalismo é dominado essencialmente pela mudança econômica resultante do impacto do processo de inovação (Rosenberg, 1994). Inovação baseada no progresso técnico, o qual, segundo Dosi (1988), é fator determinante para a competitividade internacional.

\section{Invenções e inovações tecnológicas e propriedade intelectual}

As invenções e inovações tecnológicas, ao longo da história, sempre foram vistas com certa reserva e desconfiança pela humanidade. Observa-se, entretanto, que essas resistências tendiam a desaparecer quando as pessoas começavam a perceber vantagens materiais, econômicas ou militares nas novas ideias. ${ }^{3}$ Verifica-se

\footnotetext{
${ }^{3}$ A Classificação Internacional de Patentes teve suas primeiras discussões no início dos anos 1920. O texto da primeira edição da CIP foi estabelecido de acordo com a convenção europeia
} 
que prêmios e estímulos por parte dos governos, bem como gastos de indivíduos com pesquisas aplicadas, tornaram-se uma constante. Nos últimos 60 anos foi sendo implementada nos países mais evoluídos, de forma cada vez mais consistente, a aplicação do conhecimento científico para fomentar o desenvolvimento tecnológico e a inovação. As atividades de P\&D seriam, então, o iniciador e o indicador fundamental da inovação.

Verifica-se, no campo da propriedade intelectual, que ocorreram mudanças significativas a partir do começo da década de 1980. As empresas multinacionais, a partir daquela penúltima década do século $\mathrm{XX}$, intensificam suas estratégias de globalização do mercado. Isso foi responsável pelo aumento dos gastos em investimentos de pesquisa e desenvolvimento (P\&D) em setores relacionados às novas tecnologias. A internacionalização dos mercados passa a exigir tanto a liberalização dos fluxos de mercadorias, serviços e capitais, por um lado, como um nível mais elevado de harmonização nas normas que definem o ambiente institucional no âmbito da concorrência, com destaque para o sistema de propriedade industrial. Com o aumento da participação dos gastos em investimentos de pesquisa e desenvolvimento nos novos produtos, as patentes passam a representar um fator importante no cálculo de taxa de rentabilidade privada do investimento. A tecnologia, dessa forma, torna-se um fator primordial na quantificação das vantagens comparativas nos mercados mundiais. Assim, a garantia obtida com a proteção ao conhecimento por meio do sistema de patenteamento passa a ter uma enorme importância na estratégia concorrencial das empresas (Matias-Pereira, 2004, 2011; Matias-Pereira et al., 2006).

A mudança técnica é um fator essencial na estruturação dos padrões de transformação da economia. Verifica-se, entretanto, que a tecnologia não é um bem livre, visto que sua apropriação decorre do nível acumulado de conhecimento, dos processos passados de aprendizado, das experiências das empresas e do próprio meio institucional, que pode ou não funcionar como um elemento redutor da incerteza das decisões de investimento em novos processos ou produtos (Freeman e Perez, 1988). Deve-se considerar, ainda, que os distintos segmentos industriais se diferenciam em termos de sua capacidade de promover difusão tecnológica. Assim, o avanço do progresso tecnológico repercute positivamente no processo de crescimento econômico.

para a classificação internacional de patentes em 1954. A primeira edição é datada de 1969. A classificação é periodicamente revisada a partir de reuniões de peritos dos países-membros da Organização Mundial da Propriedade Intelectual (Ompi). Essa classificação pode ser acessada nos sites do Instituto Nacional de Propriedade Industrial (Inpi) e da Ompi. Veja portal do Inpi: $<$ www.inpi.gov.br $>$. 
Observa-se que o debate da função do sistema de patentes não é uma coisa nova (Penrose, 1951). O que fica evidente nesse debate, na atualidade, é a elevada prioridade conferida ao sistema de proteção aos direitos de propriedade intelectual por todos os países, em especial ao sistema de patenteamento, tanto em nível interno como em nível internacional.

A tecnologia é um fator preponderante na determinação das vantagens comparativas dos países no comércio mundial. O que não é uma proposição nova. A teoria do hiato tecnológico (Posner, 1961) e a do ciclo do produto (Vernon, 1966, 1970) já apontavam a forma de difusão do progresso tecnológico como um dos fatores subjacentes ao padrão e à dinâmica do comércio internacional. A diferença é que, na nova etapa tecnológica, o principal fator de produção é o conhecimento ou a informação (Bifani, 1989). Neste sentido, cresce o valor econômico do conteúdo de conhecimento embutido em novos processos ou produtos. E, logo, aumenta também a relevância da propriedade industrial sob dois aspectos. Primeiro, porque essa permite a proteção privada do novo conhecimento. E, segundo, porque confere a possibilidade de extrair rendas através da propriedade dos novos conhecimentos.

Deve-se ressaltar que nem toda patente corresponde a uma invenção. $\mathrm{Na}$ verdade, uma grande parcela de patentes decorre de pequenas inovações realizadas em equipamentos e processos existentes (Kim, 1997).

\section{Indicadores de ciência, tecnologia e inovação do Brasil}

Torna-se possível argumentar que o Brasil encontra-se numa posição intermediária entre os países que buscam colocar a produção de conhecimento no centro do desenvolvimento econômico e social. Os recursos aplicados em ciência, pesquisa e fomento tecnológico representam 1\% do PIB, média semelhante à de nações como a Espanha (0,94\%), mas muito distante das maiores economias, como os Estados Unidos (2,7\%) e Japão (3\%), ou dos tigres asiáticos, como a Coreia do Sul (2,5\%). Nesses países, por outro lado, a iniciativa privada, em especial a indústria, responde por $63 \%$ dos investimentos em pesquisa e tecnologia, enquanto nas nações intermediárias o governo assume cerca de 60\% dessas inversões no setor. Dos investimentos aplicados em P\&D no Brasil (Organização para a Cooperação Econômica e o Desenvolvimento, 2005 ), o setor público foi responsável por $63 \%$, enquanto os restantes $37 \%$ ficaram por conta do setor privado. Os investimentos feitos em P\&D naquele ano chegaram a 1,07\% do PIB brasileiro. A taxa histórica dos dispêndios governamentais em P\&D no Brasil é de 0,8\% do PIB (Brasil, 2004b). 


\section{Propriedade intelectual e registro de patentes no mundo}

Observa-se que a propriedade intelectual alcançou sua atual importância em decorrência das inúmeras e sistemáticas evoluções em seus conceitos. Entre os fatores que têm atribuído maior valor à propriedade intelectual destacam-se: sua visibilidade política, devido à grande importância econômica para os países; e a constatação de que os bens imateriais superaram a tradicional estimativa concedida aos bens materiais e imóveis. Verifica-se, dessa forma, que os bens intangíveis de uma indústria, em geral, são mais valiosos que o conjunto de seus ativos materiais. Essa realidade foi a responsável pela acelerada evolução do sistema de registro de patentes no mundo, conforme se pode verificar na discussão a seguir.

A Organização Mundial de Propriedade Intelectual (World..., 2011b) define a patente como um documento expedido por um órgão governamental, que descreve a invenção e cria uma situação legal, na qual a invenção patenteada pode normalmente ser explorada (fabricada, importada, vendida e usada) com autorização do titular. Nesse sentido, o requisito de patenteabilidade se apresenta como a principal característica do documento de patente. Isso significa que pode ser patenteável a invenção que atenda aos requisitos de novidade, ou seja, aquilo que não tenha sido divulgado antes. Parte-se do entendimento de que ela seja inédita: que ainda não tenha existido, que possua atividade inventiva e aplicação industrial, tornando-se passível, portanto, de ser comercializada. Uma invenção pode ser considerada nova quando não está inserida no estado da técnica, e este é constituído por todo o registro de acesso público antes da data de depósito do pedido de patente, por descrição escrita ou oral, por uso ou qualquer outro meio, no país de origem ou no exterior.

\section{Ranking de registro de patentes no USPTO e no PCT/WIPO}

Observa-se que a capacidade de patenteamento dos países, na atualidade, tem uma forte correlação com seu nível de desenvolvimento. Embora os dados divulgados pelo escritório norte-americano de patentes - United States Patent and Trademark Office (USPTO, 2005), no período de 1980-2004 - mostrem que ocorreu uma queda no crescimento do número de patentes concedidas nos países do G7 (EUA, Inglaterra, França, Alemanha, Itália, Canadá e Japão), a diferença em termos de patenteamento quando comparados ao resto do mundo ainda é muito grande. Em 2007 foram feitos 214.807 pedidos estrangeiros de patentes depositados no Escritório de Marcas e Patentes do Departamento de Comércio dos Estados Unidos (USPTO, 2007). 
Registre-se que os países em desenvolvimento estão em ascensão nessas estatísticas de patenteamento do USPTO (2005). Nesses dados podemos verificar que países emergentes, como Taiwan e Coreia do Sul, em 2004, que na década de 1980 não tinham nenhuma expressão, apareciam como grandes patenteadores mundiais, ocupando o 4o e o 5o lugares no ranking da USPTO. No período de 2005-07 o Brasil teve 288 patentes concedidas no USPTO (2007), ${ }^{4}$ contra 359 para a Malásia, 1.410 para a Índia e 2.775 para a China. Esse baixo desempenho do Brasil em termos de patenteamento revela-se bastante preocupante, considerando o tamanho e a complexidade da economia brasileira. ${ }^{5}$

$\mathrm{O}$ ranking de registro de patentes do Patent Cooperation Treaty (PCT), acordo ligado à World Intellectual Property Organization (Wipo), que possibilita registro de patentes em 123 diferentes países, também é aceito como um importante indicador do desempenho na área de inovação tecnológica de um país. Recorde-se que o PCT facilita as solicitações no exterior ao permitir que elas cheguem a vários países a partir do primeiro depósito no Brasil. Nesse ranking em 2005 (Brasil, 2007), os Estados Unidos ocupavam o primeiro lugar, com 45.452 pedidos de patentes (33,8\% do total), seguidos por Japão ( 24.800 pedidos, ou $18,4 \%$ do total) e Alemanha (15.981 pedidos, representando $11,9 \%$ do total). Entre os países emergentes, a Coreia do Sul ocupava em 2005 a primeira posição, com 4.422 pedidos de patentes. O Brasil aparece no ranking com 275 pedidos de patentes (na sexta posição entre os emergentes), atrás da China (2.501), Índia (675), Cingapura (441) e África do Sul (360), e à frente do México (140). Veja portal da Wipo: <www.wipo.org> .

O Brasil, em 2009, com o registro de 493 patentes, apresentou crescimento de $1,6 \%$ nos pedidos de patentes no sistema internacional. Em 2010 o país teve uma queda nesse ranking, com 487 patentes registradas (World..., 2011a). O país manteve sua tendência de alta, destoando da média internacional, que registrou queda de 4,5\% no ano passado. O Brasil, no rol dos países em desenvolvimento, aparece como o quinto país com maior número de pedidos, atrás de Coreia do Sul $(8,066)$, China $(7,946)$, Índia (761) e Cingapura (594). Registre-

\footnotetext{
${ }^{4}$ O registro de patentes brasileiras no USPTO caiu 13\% no triênio 2005-07 em comparação com o triênio 2002-04, período no qual o Brasil obteve o registro de 332 patentes. Veja portal da USPTO: <http://patents.uspto.gov>.

${ }^{5} \mathrm{O}$ Brasil encerrou o ano de 2008 com um saldo de apenas 90 patentes concedidas nos EUA, contra 1.121 para a China, 545 para a Índia e 158 para a Malásia. Isso explica a queda do país para o 29 lugar na lista geral do USPTO. Deve-se destacar, também, que o depósito de patentes dentro do Brasil é igualmente reduzido. Em 2007, foram solicitadas, por todos os países, 24.107 patentes e desenhos industriais, das quais foram concedidas apenas 1.855 (Brasil, 2009).
} 
se que a queda nos pedidos internacionais em 2009 foi mais forte nos países desenvolvidos. A redução foi de $11,4 \%$ nos Estados Unidos, $11,2 \%$ na Alemanha, 3,5\% no Reino Unido, $1,6 \%$ na Suíça, $11,3 \%$ na Suécia, 5,8\% na Itália, $11,7 \%$ no Canadá, 2,2\% na Finlândia, 7,5\% na Austrália e 17,2\% em Israel.

Essa posição desconfortável do Brasil nos rankings do USPTO e do Wipo/ PCT tem sido objeto de diversos estudos no sentido de compreender por que o Brasil possui um nível de desempenho tão medíocre em pedidos de registro de patentes no mundo. Uma das explicações para o baixo desempenho do Brasil nos principais rankings de pedidos de registro de patentes no mundo (USPTO e Wipo/PCT) estaria relacionada à baixa proporção de pesquisadores que estão atuando nas empresas. Nos países desenvolvidos, até $80 \%$ dos pesquisadores e seus estudos estão localizados nas empresas, enquanto os restantes $20 \%$ se encontram na academia. No Brasil esta situação é inversa.

Observa-se, com base nos referenciais internacionais, que o Brasil possui uma base de pesquisa acadêmica competitiva (Brasil, 2004b). A base de pesquisa empresarial, entretanto, é bastante frágil. Dessa forma, o grande obstáculo a ser superado é a implementação adequada das políticas públicas orientadas para gerar estímulos para que as empresas do Brasil possam empregar cientistas e engenheiros para fazer desenvolvimento tecnológico nas empresas.

\section{Políticas públicas de proteção à propriedade intelectual}

Na medida em que as políticas e gestão de ciência e tecnologia estão a cargo do setor público, é perceptível que a avaliação da qualidade das instituições voltadas à gestão e à formulação de política científica e tecnológica encontra resistências. ${ }^{6}$ Observa-se que o Brasil ainda não conseguiu desenvolver um sistema de administração pública de gestão de propriedade intelectual compatível com as exigências das demandas num mundo globalizado.

A questão da proteção à propriedade intelectual se apresenta como uma área sensível e importante para apoiar o processo de desenvolvimento do país (Organização..., 2003). É nesse setor que estão ocorrendo, na atualidade, os maiores enfrentamentos no mundo, visto tratar-se do controle de dois fatores estratégicos para qualquer país: o domínio da tecnologia e da informação pro-

\footnotetext{
${ }^{6}$ Observa-se que a ciência, a tecnologia e a inovação no Brasil ainda não são tratadas como questões de Estado, que devem ultrapassar os governos e devem ser tratadas como compromissos que se transferem de um período governamental para outro (Matias-Pereira, 2009).
} 
prietária. São os denominados ativos intangíveis — apropriados sob a forma de títulos - , responsáveis pela geração de royalties, por meio da exploração de marcas e patentes, e copyright, pela reprodução de obras artísticas e literárias (Matias-Pereira e Kruglianskas, 2004).

É oportuno ressaltar que a propriedade intelectual compreende todas as regras relativas à proteção dos direitos de propriedade industrial, os direitos de autor e do savoir-faire. Nesse sentido, a patente de invenção, além de estimular a atividade inventiva e facilitar o intercâmbio de conhecimento, também desempenha um papel importante na circulação de informações científicas e técnicas e contribui, assim, para o enriquecimento do patrimônio tecnológico da sociedade (Chavanne e Burst, 1993).

A propriedade industrial pode ser aceita como um instrumento legal que estimula uma maior competitividade entre indivíduos ou empresas e promove a concorrência e o avanço tecnológico. Assim, a propriedade industrial é importante para o equilíbrio das relações entre indústrias, na medida em que define mecanismos de colaboração entre estas e com universidades, institutos de pesquisas e outras entidades congêneres. Considerando que o desenvolvimento de novos produtos e processos, em sua maioria, necessita de elevados investimentos, a proteção por meio da propriedade industrial passou a ter cada vez mais importância no cenário internacional, visto que se tornou um fator crítico de vantagem competitiva para o país.

A patente, por sua vez, é um privilégio legal concedido pelo Estado aos inventores e a outras pessoas detentoras dos direitos de exploração de um produto, de um novo processo de fabricação ou de um aperfeiçoamento de produto ou processo existente. A carta patente é uma instituição econômica e jurídica que: define a propriedade tecnológica; garante o mercado para seu titular, por prazo determinado; incentiva e obriga a sociedade em geral a uma contínua renovação tecnológica.

\section{Processo de modernização do Instituto Nacional da Propriedade Industrial (Inpi)}

Observa-se que o processo de globalização está afetando duramente o sistema de patentes na maioria dos países no mundo. Essa crise instalada no sistema de patentes mundial também está se refletindo no Brasil, nos aspectos qualitativos e quantitativos. Nos aspectos qualitativos verifica-se a crescente intenção de patentear descobertas e não invenções; as interpretações distorcidas dos conceitos de utilidade e não obviedade etc. Quanto aos aspectos quantitativos, 
verifica-se nas últimas duas décadas uma elevação significativa do número de pedidos de patentes depositadas; a entrada no sistema de propriedade intelectual de novas áreas de patenteabilidade, como biotecnologia, nanotecnologia, informática; o crescimento da complexidade dos pedidos de patente; o maior número de países em que um mesmo pedido é depositado, entre outras. Isto tem refletido sobre a qualidade dos serviços prestados pelos órgãos encarregados de registrar as patentes (Ávila, 2007). Demora na análise dos pedidos, elevação do custo de patenteamento e expedição de patentes duvidosas. Esses problemas assinalados podem ser visualizados nos relatórios de desempenho do Inpi, divulgados no período de 1999 a 2009 (Brasil, 2009).

Diante desse contexto, ganhou relevância a necessidade do fortalecimento das políticas de desenvolvimento e inserção internacional do Brasil. Esse cenário levou o governo federal a dar início à implementação de um programa de reestruturação do Inpi em 2004, logo após a implantação da Política Industrial, Tecnológica e de Comércio Exterior (Pitce). O objetivo do programa foi dividido em duas fases: busca da eficiência e para a facilitação do acesso dos cidadãos e empresas aos serviços prestados, além do desenvolvimento de uma cultura de propriedade intelectual que favorecesse o crescimento e a inserção internacional das empresas brasileiras na economia global (Brasil, 2009:9).

\section{O papel do Inpi}

O Instituto Nacional da Propriedade Industrial (Inpi), ${ }^{7}$ autarquia federal vinculada ao Ministério do Desenvolvimento, Indústria e Comércio Exterior (MDIC), é o órgão responsável no Brasil por executar as normas que regulam a propriedade industrial, levando em consideração sua função social, econômica, jurídica e técnica. Dentro dessas atribuições, estão incluídas tarefas como a concessão de registros de marcas e patentes. Dessa forma, o Inpi é o único órgão no âmbito nacional responsável pelo registro de patentes de inovações tecnológicas.

\footnotetext{
${ }^{7}$ O Instituto Nacional da Propriedade Industrial (Inpi) é responsável por registros de marcas, concessão de patentes, averbação de contratos de transferência de tecnologia e de franquia empresarial, e por registros de desenho industrial e indicações geográficas, de acordo com a Lei da Propriedade Industrial (Lei o 9.279/1996), além de registros de programas de computador (Decreto no 2.556/1998) e de topografia de circuitos integrados (Lei no 11.484/2007). Disponível em: <www.inpi.gov.br>.
} 
O Inpi, em relação a suas metas de disseminação e apoio ao desenvolvimento, tem a responsabilidade de buscar ampliar o depósito de patentes de invenções e desenhos industriais por empresas e universidades brasileiras; ampliar o uso do PCT por brasileiros; ampliar o depósito de marcas e desenhos industriais brasileiros no exterior; e criar indicações geográficas brasileiras.

Registre-se que o Inpi é o responsável pelo Programa 0393 - Desenvolvimento do Sistema de Propriedade Intelectual do Plano Plurianual (PPA) no âmbito do governo federal. O objetivo do programa é promover o uso estratégico e reduzir a vulnerabilidade do sistema de propriedade intelectual de modo a criar um ambiente de negócios que estimule a inovação e promova o crescimento e o aumento da competitividade das empresas e favoreça o desenvolvimento tecnológico, econômico e social. O público-alvo do referido programa é formado por pessoas físicas e jurídicas nacionais e estrangeiras que podem ser beneficiadas pelo registro, proteção, uso e comercialização de propriedade intelectual em território brasileiro. A propriedade intelectual é responsável, na atualidade, pela maior parte do valor gerado pelas empresas modernas, especialmente nos segmentos mais dinâmicos, aqueles referentes a produtos diferenciados por marcas e outros signos distintivos, design e conteúdo tecnológico ou autoral (Brasil, 2009).

Para o Inpi (Brasil, 2009), a adequada administração dos sistemas de propriedade industrial, dos direitos de autor e conexos (relativos ao software e às indústrias criativas em geral) e das demais formas de propriedade intelectual é fundamental para incentivar o investimento em pesquisa e desenvolvimento e nas atividades criativas em geral; tornar viável a cooperação tecnológica entre diferentes empresas e entre empresas e instituições de pesquisa; proporcionar o acesso das empresas brasileiras ao sistema de propriedade intelectual, criando condições para que estas venham a desenvolver, adquirir e comercializar tecnologia e outros ativos de propriedade intelectual e a obter, assim, um nível de inserção na economia internacional superior ao que se pode obter nos mercados de commodities; evitar que se cometam equívocos na concessão de direitos, que venham a minar a previsibilidade e, portanto, não incentivem investimentos em inovação e marketing, assim como onerem indevidamente os consumidores; e promover a circulação da informação e do conhecimento necessário para o desenvolvimento das empresas.

\section{Síntese das principais ações desenvolvidas pelo Inpi - 2007-10}

O Inpi alcançou, conforme delineado no Relatório de Gestão de 2009, metas importantes na área de propriedade intelectual, com destaque para: a 
consolidação do sistema de processamento de marcas e a estruturação dos serviços de exame internacional de patentes, no âmbito do Tratado de Cooperação em Matéria de Patentes (PCT, na sigla em inglês); a aprovação pelo Banco Interamericano de Desenvolvimento (BID) do projeto de integração de escritórios de propriedade intelectual de oito países sul-americanos, para estabelecer uma plataforma cooperativa para o exame de marcas e patentes; a contratação de novos examinadores de patentes e de pesquisadores seniores que se dedicarão às atividades de pesquisa e ensino de pós-graduação; e a ampla disseminação da importância da propriedade intelectual para instituições de pesquisa e empresas brasileiras de diferentes portes e setores de atividade.

Evidencia-se, em relação à produtividade e informatização em patentes, que o Inpi (Brasil, 2009) vem ampliando sua produtividade. As patentes concedidas cresceram 52\% de 2007 para 2008, subindo de 1.855 para 2.824. Em 2009, acréscimo de mais $11 \%$, chegando a 3.153, e, em 2010, o índice foi de 3.620. O crescimento da capacidade do Inpi é necessário para atender à ampliação da demanda por patentes, tanto por brasileiros quanto por estrangeiros; prova disso é que os pedidos passaram de 23.221 para 26.232 - acréscimo de $12,9 \%$ entre 2007 e 2008. A estimativa para 2010 é de 30 mil novos pedidos. O Inpi investe, desde 2008, na adaptação para o Brasil do sistema Eptos, desenvolvido originalmente pelo Escritório Europeu de Patentes (EPO). O sistema compreende um conjunto de ferramentas de automação para gestão dos procedimentos num órgão de propriedade industrial, incluindo o depósito eletrônico e o processamento dos pedidos. Isso resultará na realização de todo o andamento do pedido pela internet, incluindo aspectos legais. Em dezembro de 2010, teve início a implantação do sistema de exame eletrônico de patentes, com os examinadores trabalhando com todos os documentos digitalizados. A próxima etapa, de implantação do controle eletrônico do fluxo de trabalho, será acompanhada de nova organização dos procedimentos de exame, com otimização e aumento da produtividade.

Observa-se que o Inpi (Brasil, 2011), em busca de agilidade nas análises de patentes, vem desenvolvendo diversas ações, com destaque para a busca de parcerias com outros institutos nacionais de propriedade industrial. É o caso, por exemplo, do Patent Prosecution Highway (PPH), que está sendo discutido pelo Inpi com os Estados Unidos, México, Portugal, Espanha e Japão. O PPH permite realizar o trabalho em menor tempo, visto que o examinador de um país pode ter acesso à busca internacional que foi feita pelo pesquisador de outra nação, servindo como subsídio para seu trabalho. Todos os examinadores 
devem fazer a mesma busca, já que uma patente só pode ser concedida se não houver nada igual ou muito semelhante em nenhuma parte do mundo. Registre-se, ainda, que o segundo país não precisará analisar as reivindicações que já tiverem sido indeferidas no primeiro, e que o pedido somente será analisado pelo PPH a partir da solicitação do requerente.

Outro avanço relevante no esforço de modernização do Inpi é o lançamento do sistema de aquisição de dados PCT (Sisad-PCT), que permitirá o cadastro mais rápido dos pedidos de patentes que chegam ao instituto a partir do exterior, via Tratado de Cooperação em Matéria de Patentes (PCT), o que contribuirá para acelerar o processo. Trata-se de um sistema que possibilita a aquisição automática de dados com o acesso a todas as informações de um pedido PCT, através da comunicação com a base de dados da Organização Mundial da Propriedade Intelectual (Ompi). Veja portal do Inpi: $<$ www.inpi.gov.br $>$.

\section{Principais ações para a aceleração das atividades do Inpi}

A análise do planejamento estratégico do Inpi (Brasil, 2011) indica que a próxima etapa de desenvolvimento do instituto e do sistema brasileiro de propriedade industrial (ou de propriedade intelectual de interesse da indústria brasileira) será caracterizada pela consolidação dos resultados alcançados nos últimos anos e pelo avanço das reformas estruturais. Essas iniciativas têm por objetivos a eficiência e a qualidade nos exames e a promoção do uso estratégico da propriedade industrial por brasileiros e residentes no Brasil. A etapa 2011-14 também deverá ser marcada pelo aprofundamento da inserção internacional do Inpi, com ênfases na colaboração e integração regional (entre Inpis e afins) e no desempenho de papéis de maior relevância no contexto multilateral global.

Conforme vislumbrado no Planejamento Estratégico em elaboração, a ação futura poderá ser organizada em quatro dimensões principais: eficiência e qualidade operacional; promoção do uso estratégico da propriedade intelectual (PI) por brasileiros e residentes; integração regional; e aperfeiçoamento do sistema global de PI e reposicionamento do Inpi. A etapa 2011-14 também deverá ser marcada pelo aprofundamento da inserção internacional do Inpi, com ênfases na colaboração e integração regional (entre Inpis e afins) e no desempenho de papéis de maior relevância no contexto multilateral global. 


\section{Percepção dos empresários sobre inovação e propriedade intelectual: análise dos resultados da pesquisa qualitativa}

Tendo como objetivo identificar as principais características e fragilidades da gestão das políticas públicas na área de proteção à propriedade industrial, em particular sobre patenteamento, realizaram-se 33 entrevistas qualitativas com dirigentes de empresas industriais de grande, médio e pequeno porte, todas localizadas no estado de São Paulo. As entrevistas foram realizadas nos meses de outubro e novembro de 2008. Apesar de tratar-se de uma amostragem limitada, somente nas empresas de grande porte se observou que existe uma consciência da importância da inovação, traduzida tanto pelo patenteamento de suas invenções como pela vigilância sobre o mercado em termos de privilégios patenteados por terceiros. Registre-se que as entrevistas foram realizadas por meio da internet. A pergunta formulada foi: qual a percepção sobre a importância e o nível de prioridade dada por sua empresa para a questão do patenteamento? Os informantes discorreram livremente sobre o assunto em pauta. O tratamento dos dados obedeceu aos seguintes passos: ordenação e classificação dos dados e análise final. Os resultados obtidos na pesquisa qualitativa são importantes para reforçar as nossas conclusões sobre o nível de conhecimento da indústria acerca das questões envolvendo a gestão da proteção da propriedade industrial e as dificuldades e problemas enfrentados nesta área. ${ }^{8}$

\section{O que se destaca das entrevistas qualitativas}

i. A propriedade industrial — área do direito identificada como "marcas e patentes" - é aceita por unanimidade dos entrevistados como uma área importante para as atividades industriais e empresariais dos mais diversos

\footnotetext{
${ }^{8}$ Foram importantes para elevar o nível de consistência deste artigo as exposições dos empresários, especialistas e pesquisadores que participaram do 3을 Encontro Nacional da Indústria — Enai 2008, realizado em Brasília, nos dias 28 e 29 de outubro de 2008. O evento teve como objetivo avaliar, no contexto da crise financeira mundial, alternativas para maior competitividade da indústria nacional, além de maior integração do setor. Portal: <www.cni.org.br>.

Devemos destacar, também, as contribuições dos expositores da IX Conferência Anpei de Inovação Tecnológica, promovida pela Associação Nacional de Pesquisa, Desenvolvimento e Engenharia das Empresas Inovadoras (Anpei), realizada entre os dias 8 e 10 de junho de 2009, em Porto Alegre (RS). O evento focalizou o desafio atual presente às empresas e aos profissionais que atuam na área de inovação. Veja portal da Anpei: <www.anpei.org.br>.
} 
setores. Apesar de valorizada e utilizada como instrumento de estratégia concorrencial e de competitividade nos países mais desenvolvidos, afirmam os entrevistados que o sistema de propriedade industrial é subutilizado e desconhecido por substancial parcela do empresariado.

ii. A falta de proteção adequada de marcas, patentes e desenhos industriais, tanto no Brasil como no exterior, é vista por todos os entrevistados como bastante prejudicial à competitividade da indústria brasileira. Isso tende a dificultar ou impedir a recuperação de investimentos em pesquisa e desenvolvimento e pode ser causa de vultosos prejuízos, perda de clientela e de oportunidades comerciais.

iii. As empresas e instituições nacionais, em geral, parecem não estar adequadamente atentas para as fortes mudanças ocorridas no cenário mundial, com profundo impacto sobre o comércio, bem como no acesso às tecnologias, onde a propriedade intelectual tem sido objeto de importância crucial na competitividade. Fica evidenciado nas entrevistas que, apesar de o mercado externo ser muito visado pela indústria, não há uma preocupação acentuada com a proteção da propriedade industrial no exterior. Isso tem criado entraves para colocação de produtos brasileiros em outros mercados.

iv. Todos os entrevistados sustentam a importância de o Estado orientar as políticas públicas na área de propriedade industrial, principalmente no que se refere à reestruturação e fortalecimento do Inpi, com vista a tornar mais eficiente a administração do sistema público de proteção da propriedade industrial no Brasil.

v. Os entrevistados sustentam a importância da realização de estudos consistentes pelo segmento empresarial, em parceria com o Inpi, com vista a disponibilizar informações sobre a matéria propriedade industrial, para subsidiar o governo e o setor produtivo.

vi. As empresas, no que se refere à inovação tecnológica, necessitam rever padrões de comportamentos, como adoção de decisões que buscam resultados imediatos, aversão ao risco e egoísmo colaborativo.

vii. É preciso que empresas priorizem, em suas estruturas organizacionais, definições políticas ou diretrizes e suporte para a gestão das ações de Propriedade Intelectual/Patentes. Para isso, é preciso que as empresas adotem políticas mais agressivas, no que se refere ao uso do Sistema de Patentes como proteção legal, bem como fonte de informação tecnológica e de mercado.

viii. Para uma grande parcela dos entrevistados (especialmente os professores pesquisadores) é importante intensificar as ações para estimular as instituições tecnológicas, de pesquisa e universidades a fortalecerem seus núcleos de gestão de tecnologia/patentes. É preciso, também, disseminarem a 
cultura da propriedade intelectual e utilizarem indicadores de desempenho que privilegiem o desenvolvimento de novos produtos e processos, e a parceria com indústrias como forma de incrementar as inovações.

\section{Visão da indústria sobre a gestão de políticas de propriedade intelectual}

A percepção de inúmeros empresários e especialistas sobre a gestão de políticas de propriedade intelectual no Brasil, contidas nas conclusões do Congresso Brasileiro de Inovação na Indústria (Confederação Nacional de Indústria, 2005b), respalda as constatações feitas pela pesquisa qualitativa deste artigo. A síntese do documento assinala que:

As condições de operação do INPI constituem um óbice às empresas que pretendam estabelecer uma adequada gestão da sua propriedade intelectual. O tempo médio de 9 anos para a obtenção de uma patente e de 5,5 anos para a concessão de marca é um indicativo claro das dificuldades atualmente observadas. A isso se soma também o custo do registro de patentes, que é elevado para as pequenas empresas e que requer a contratação de assessoria jurídica especializada. O INPI possui poucos funcionários e ainda opera com níveis de informatização insuficientes. Por outro lado, há a necessidade de uma maior disseminação da cultura de proteção da propriedade intelectual entre as empresas e as instituições de ensino e pesquisa, o que tem levado em muitos casos a uma proteção inadequada dos conhecimentos gerados.

\section{Conclusões}

As deficiências evidenciadas na avaliação do desempenho da gestão do sistema de proteção à propriedade intelectual no país ainda são preocupantes. Essa análise revelou que, entre outras deficiências, existem dificuldades na administração dessas políticas, em particular, no segmento de registro de patentes. Constata-se, assim, que políticas públicas orientadas para a área de propriedade intelectual não estão cumprindo adequadamente seu papel, em termos institucionais e de geração de estímulos à inovação. As pressões da sociedade organizada exigindo o aprofundamento nas mudanças, o redimensionamento e o fortalecimento do Inpi para estimular a incorporação tecnológica na produção e a inovação - que se apresenta como o principal foco da política industrial — dão respaldo parcial a esta afirmação. 
Ficou razoavelmente evidenciado que, na busca de fomentar a C, T\&I no país, tanto a Lei de Inovação como as Diretrizes da Política Industrial e Tecnológica, o Plano de Ação de Ciência, Tecnologia e Inovação para o Desenvolvimento Nacional - 2007-10 e a Política de Desenvolvimento Produtivo fazem parte de um ciclo, que partiu da discussão focada nos recursos, atingiu os aspectos institucionais, que agora precisam ser implementados. Observa-se, após a regulamentação da Lei de Inovação, que ainda existem aspectos que necessitam um maior detalhamento, de forma a preservar a identidade tanto das universidades quanto das indústrias e empresas, para que, de fato, ela possa vir a se tornar um instrumento relevante de fomento à política industrial e tecnológica do país.

É inegável que a dinamização do uso da propriedade intelectual precisa de suporte e estímulos institucionais. As políticas públicas de proteção à propriedade intelectual se fazem necessárias, especialmente para as universidades e os centros de pesquisas e para as indústrias, visto que nesse campo ocorre grande parte da criação e inovação tecnológica e cultural, a partir de teses, conceitos e teorias potencialmente geradores de tecnologias inovadoras. A geração de estímulos e de parcerias para fomentar as ações conjuntas entre as universidades e os centros de pesquisa e o segmento industrial é essencial para facilitar o intercâmbio de informações específicas para agilizar os processos de pedidos de patente e a definição dos parâmetros de comercialização e transferência de tecnologia.

O baixo nível de conhecimento e interesse dos dirigentes de grande parcela das empresas brasileiras no campo da propriedade intelectual vem gerando riscos desnecessários nas exportações de seus produtos. Diante das deficiências e fragilidade do sistema de gestão de políticas de proteção à propriedade intelectual, argumentamos que é essencial que o país continue se modernizando nessa área, em particular no segmento de registro de marcas e patentes. Torna-se essencial que o país intensifique a utilização da proteção à propriedade intelectual como um instrumento de suporte ao processo de desenvolvimento socioeconômico. Essas mudanças devem ser implementadas, necessariamente, por meio da gestão de políticas públicas consistentes.

\section{Referências}

ÁVILA, Jorge. O Inpi e a propriedade intelectual no Brasil: resultados e metas. In: CONGRESSO BRASILEIRO DE INOVAÇÃO NA INDÚSTRIA, II, 2007, São Paulo. Anais... 2007. Disponível em: <www.cni.org.br>. 
. Open innovation e o Sistema Nacional de Inovação. In: OPEN INNOVATION SEMINAR 2008. Anais... São Paulo: FGV, 2008.

. Instituto Nacional de Propriedade Industrial. Balanço \& perspectivas. Rio de Janeiro: Inpi/MDIC, 2011. Disponível em: <www.inpi.gov.br>. Acesso em: 30 jan. 2011.

. Instituto Nacional de Propriedade Industrial (Inpi). Relatório de gestão de 2009. Rio de Janeiro: Inpi/MDIC, 2009. Disponível em: <www.inpi.gov.br>. Acesso em: 11 jan. 2011.

BRASIL. Ministério do Desenvolvimento, Indústria e Comércio Exterior (MDIC). Diretrizes de política industrial e tecnológica e de comércio exterior. Brasília: MDIC, 2004a.

. Ministério da Ciência e Tecnologia (MCT). Indicadores sobre ciência e tecnologia no Brasil. 2004b. Disponível em: <www.mct.gov.br>. Acesso em: 18 jan. 2011.

. Ministério da Ciência e Tecnologia. Plano de ação de ciência, tecnologia e inovação para o desenvolvimento nacional - 2007-2010. Brasília: MCT, 2007.

. Ministério do Desenvolvimento, Indústria e Comércio Exterior (MDCI). Política de desenvolvimento produtivo. Brasília: MDIC, 2008. Disponível em: <www. mdic.gov.br>. Acesso em: 21 jan. 2011.

BARBIERI, J.C. Utilização de patentes no Brasil. São Paulo: Eaesp/Fundação Getulio Vargas, 1988. (Relatório de Pesquisa n. 43)

BIFANI, P. Intellectual property rights and international trade. In: URUGUAY ROUND. New York: Unctad/United Nations, 1989.

BRITO CRUZ, Carlos H. Ciência e tecnologia no Brasil. Revista USP, São Paulo, n. 73, p. 58-90, mar./maio 2007.

CHAVANNE, Albert; BURST, Jean-Jacques. Droit de la proprieté industrielle. Paris: Précis-dalloz, 1993.

CONFEDERAÇÃO NACIONAL DA INDÚSTRIA. Políticas públicas de inovação no Brasil: a agenda da indústria. São Paulo: CNI, 2005a. p. 1-21.

. Inovar para crescer: propostas para acelerar o desenvolvimento tecnológico da indústria brasileira. In: CONGRESSO BRASILEIRO DE INOVAÇÃO NA INDÚSTRIA, II, 2007, São Paulo. Anais... 2007. Disponível em: <www.cni.org. br/portal/data/pages/FF80808121EC4838012207CC96DF4C5F.htm >. Acesso em: 17 jan. 2011.

. Gestão da propriedade intelectual. In: CONGRESSO BRASILEIRO DE INOVAÇÃO NA INDÚSTRIA, I, 2005, São Paulo. Anais... 2005b. p. 1-47. 
COUTINHO, Luciano; FERRAZ, João Carlos (Coord.). Estudo da competitividade da indústria brasileira. Campinas/São Paulo: Papirus/Editora da Universidade Estadual de Campinas, 1994.

DAHLMAN, Carl J. New dimensions of innovation and competitiveness policies: international experiences. In: CONGRESSO BRASILEIRO DE INOVAÇÃO NA INDÚSTRIA, II, 2007, São Paulo. Anais... 2007. Disponível em: <www.cni.org.br>. DOSI, G. Sources, procedures and microeconomic effects of innovation. Journal of Economic Literature, v. 27, p. 1126-1171, 1988.

ERBER, F.S. (1982). A propriedade industrial como instrumento de competição entre empresas e objeto de política estatal: uma introdução. Pesquisa e Planejamento Econômico, Rio de Janeiro, v. 12, n. 3, 1982.

FERREIRA, Carlos E.M. et al. Estudo da viabilidade técnica e econômica da inventiva nacional: projeto Inventiva. Relatório Final. Brasília: MICT/STI, Inpi, Sebrae, Fiesp/Ciesp, 1998.

FREEMAN, C.; PEREZ, C. Structural crises of adjustment: business cycles and investment behavior. In: DOSI, G. et al. (Ed.). Technical change and economic theory. London: Pinter, 1988.

FRISCHTAK, C. The protection of intellectual property rights and industrial technology development in Brazil. Washington: World Bank, 1989. (Industry Series Papers no 13, Industry and Energy Department)

FRITSCH, W.; FRANCO, G. Foreign direct investment in Brazil. Paris: Ocde, 1991.

GUIMARÃES, E.A. Políticas de inovação: financiamento e incentivos. Brasília: Ipea, 2006. (Texto para Discussão 1.212, p. 1-69)

JAGUARIBE, Roberto. Infraestrutura tecnológica para a inovação e a competitividade. Workshop 1. In: SEMINÁRIO INTERNACIONAL CELSO FURTADO - POLÍTICA INDUSTRIAL E OS DESAFIOS PARA A COMPETITIVIDADE, 2006, São Paulo. Anais... 2006.

KIM, Linsu. Imitation to innovation: the dynamics of Korea's technological learning. Boston: Harvard Business Scholl Press, 1997.

. Tecnologia, aprendizado e inovação: as experiências das economias de industrialização recente. São Paulo: Editora Unicamp, 2005.

KURZ, R. O colapso da modernização. Rio de Janeiro: Paz e Terra, 1992.

MATIAS-PEREIRA, J. Brazilian new patterns of industrial, technological and foreign trade policy. Journal of Technology Management Innovation, v. 1, n. 3, p. 17-28, 2006. Disponível em: <www.jotmi.org > . 
. Curso de administração estratégica. São Paulo: Atlas, 2011.

. Management of Brazilian system for protection to intelectual property: fragilities and perspectives for the sector of patents and trademarks registry. In: ALTEC, 2009, Cartagena. Anais... 2009.

MARCOVITCH, Jacques. Administração em ciência e tecnologia. São Paulo: Edgard Blücher, 1983.

; KRUGLIANSKAS, Isak. A Lei de Inovação como instrumento de suporte à política industrial e tecnológica do Brasil. Revista de Administração de Empresas (RAE-eletrônica), p. 1-18, abr./jul. 2005. Disponível em: <www.rae.com.br>. Acesso em: 15 jan. 2011.

; _. Gestão de políticas de proteção à propriedade intelectual no Brasil. In: SIMPÓSIO DE GESTÃO DE INOVAÇÃO TECNOLÓGICA, XXIII, Curitiba. Anais... 2004. p. $1-15$.

MENDONÇA, Maurício. Políticas públicas de inovação no Brasil: a agenda da indústria. Revista Parcerias Estratégicas, Brasília, n. 21, p. 5-32, dez. 2005.

NELSON, R.R.; WINTER, S.G. An evolutionary theory af economic change. Estados Unidos: Harvard University Press, 1982.

; ___ Uma teoria evolucionária da mudança tecnológica. Campinas: Editora Unicamp, 2005.

ORGANIZAÇÃO PARA A COOPERAÇÃO ECONÔMICA E O DESENVOLVIMENTO (OCDE). Main science and technology indicators, n. 2. Paris: Ocde, 1997.

. Managing national innovation systems. Paris: Ocde, 1999.

. Brazil: economic survey. Paris: Ocde, 2001.

. Science, technology and industry outlook 2005. Paris: Ocde, 2005.

. Science, technology and industry scoreboard. Paris: Ocde, 2003.

. Technology and industrial performance. Paris: Ocde, 1996.

PAVITT, K. Sectorial patterns of technical change. Research Policy, n. 13, p. 343373, 1984.

. The social shape of the national science base. Research Policy, v. 27, n. 8, p. 793-805, 1998.

. What makes basic research economically useful? Research Policy, v. 20, n. 2, p. 109-119, 1991. 
PATEL, P.; PAVITT, K. National innovation systems: why they are important, and how they might be measured and compared. Economics of Innovation and New Technology, v. 3, n. 1, p. 77-95, 1994a.

. Uneven (and divergent) technological accumulation among advanced countries: evidence and a framework of explanation. Industrial and Corporate Change, v. 3, n. 3, p. 759-787, 1994b.

; __ . Patterns of technological activity: their measurement and interpretation. In: STONEMAN, P. (Ed.). Handbook of the economics of innovation and technological change. Oxford: Blackwell, 1995.

PENROSE, Edith. The economics of international patent system. Baltimore: The Johns Hopkins Press, 1951.

POSNER, M.V. International trade and technical change. Oxford Economic Papers, Oct. 1961.

ROMER, Paul M. Endogenous technological change. Journal of Political Economy, v. 98, n. 5, p. 71-102, 1990.

. Growth based on increasing returns due to specialization. American Economic Review, n. 77, p. 56-62, 1987.

. Increasing returns and long-run growth. Journal of Political Economy, v. 94, n. 5, p. 1002-1037, 1986.

. Two strategies for economic development: using ideas and producing ideas. In: THE WORLD BANK ANNUAL CONFERENCE ON DEVELOPMENT ECONOMICS, 1992. Proceedings... Washington: World Bank, 1993.

ROSENBERG, N. Exploring the black box. Cambridge: Cambridge University Press, 1994.

SCHUMPETER, J.A. A teoria do desenvolvimento econômico. São Paulo: Abril, 1982.

SHERWOOD, Robert M. Propriedade intelectual e desenvolvimento econômico. São Paulo: Edusp, 1992.

SOLOW, R. A contribution to the theory of economic growth. Quarterly Journal of Economics, v. 70, 1956. 1988.

. Growth theory: an exposition. New York/Oxford: Oxford University Press,

. Technical change and the aggregate production function. Review of Economics and Statistics, v. 39, 1957. 
TORNATZKY, L.G.; FLEISCHER, M. The process of technological innovation. Lexington: Lexington Books, 1990.

UNESCO. Organização das Nações Unidas para a Educação, a Ciência e a Cultura. Relatório Unesco sobre Ciência 2010. Brasil: Unesco, 2010. Disponível em: <www. unesco.org/science/psd>. Acesso em: 28 mar. 2011.

UNITED STATES PATENTS AND TRADEMARK OFFICE (USPTO). Annual report of the register of copyrights. 2005. Disponível em: <www.copyright.gov/reports/annual/2005/cover1.pdf>. Acesso em: 23 jan. 2009.

. Performance and accountability report. 2007. Disponível em: <www.uspto. gov/web/offices/com/annual/2007/50300_workloadtables.htm>. Acesso em: 13 jan. 2011.

VERNON, R. International investment and international trade in the product cycle. Quarterly Journal of Economics, May 1966.

(Ed.). The technology factor in international trade. New York: Columbia University Press, 1970.

WARSH, David. Knowledge and the wealth of nations. New York: W.W. Norton, 2006.

WORLD INTELLECTUAL PROPERTY ORGANIZATION (WIPO). International patent system. Monthly statisticas report May 2011. Geneva: Wipo, 2011a. Disponível em: $<$ www.wipo.int/export/sites/www/ipstats/en/statistics/pct/pdf/monthly_report. pdf > . Acesso em: 27 mar. 2011.

. Patentscope terms and conditions. Terms and conditions for the use of Wipo Patent Information Products and Services (May 5, 2011). Geneva: Wipo, 2011b. Disponível em: <http://www.wipo.int/patentscope/en/data/terms.html\#1>. Acesso em: 28 mar. 2011.

. PCT yearly review: The International Patent System in 2009. Geneva: Wipo, 2010. Disponível em: <www.wipo.int/pct/en/activity/index.html>. Acesso em: 27 mar. 2011.

. World intellectual property indicators 2010. Geneva: Economics and Statistics Division, Wipo, 2010. Disponível em: <www.wipo.int/ipstats/en/statistics/patents/>. Acesso em: 23 jan. 2011. 